\title{
Metode Pembelajaran Active Learning Tipe Problem Solving Dan Cooperative Learning Tipe Group Investigation Dalam Meningkatkan Hasil Belajar
}

\author{
${ }^{1}$ Ade Suherman ${ }^{2}$ Yuyun Susanti ${ }^{3}$ Yulianti Imaniar \\ 1adesuhermana@gmail.com \\ ${ }^{2}$ yuyunsusanti444@gmail.com \\ 3yuliantiimaniar@gmail.com \\ ${ }^{1}$ Program Studi Pendidikan Ilmu Pengetahuan Sosial \\ Institut Pendidikan Indonesia \\ Jl. Terusan Pahlawan No.32, RW.01, Sukagalih, Kec. Tarogong Kidul, Kabupaten \\ Garut, Jawa Barat 44151 \\ ${ }^{2,3}$ Program Studi Pendidikan Akuntansi Fakultas Keguruan dan Ilmu Pendidikan \\ Universitas Galuh \\ Jl. R.E. Martadinata No. 150 Ciamis
}

\begin{abstract}
This study aims to determine the differences in student learning outcomes using the Active Learning Problem Solving Type method with the learning outcomes of students using the Cooperative Learning Type Group Investigation method on posttest (experimental class 1) and posttest (experimental class 2) measurements in accounting subjects The research was conducted in class X Ak at SMK Bahrul Uluum Kawali. The method used is quantitative method, namely data in the form of numbers. The form of experimental design used in this research is Quasi Experiment, which is carried out by giving treatment to the research subject and then giving a test to the research subject. The results of the study can be concluded 1) There is a high level of improvement (with the N-Gain criteria) learning outcomes of students who use the Active Learning Problem Solving type method in the initial (pretest) and final (posttest) measurements 2) There is a moderate increase (with criteria N-Gain) learning outcomes of students who use the Cooperative Learning type Group Investigation method at the initial measurement (pretest) and the final measurement (posttest) 3) There is a significant difference between the learning outcomes of students who use the Active Learning method, the Problem Solving type with the Cooperative method Group Investigation type learning in the final measurement (posttest).

Keywords: Student Learning Outcomes, Problem Solving, Group Investigation
\end{abstract}

\section{ABSTRAK}

Penelitian ini bertujuan untuk mengetahui perbedaan hasil belajar peserta didik yang menggunakan metode Active Learning Tipe Problem Solving dengan hasil belajar peserta didik yang menggunakan metode Cooperative Learning Tipe Group Investigation pada pengukuran posttest (kelas eksperimen 1) dan posttest (kelas eksperimen 2) mata pelajaran Akuntansi. Penelitian di laksanakan di kelas X Ak di SMK Bahrul Uluum Kawali. Adapun metode yang digunakan adalah metode kuantitatif, yaitu data yang berbentuk angka. Bentuk desain eksperimen yang digunakan dalam penelitian ini adalah Quasi Eksperimen, yang dilakukan dengan memberikan perlakuan kepada subjek penelitian kemudian memberikan tes pada subjek penelitian. Hasil penelitian dapat disimpulkan 1) Terdapat peningkatan tingkat tinggi (dengan kriteria $\mathrm{N}$-Gain) hasil belajar peserta didik yang menggunakan metode Active Learning tipe Problem Solving pada pengukuran awal (pretest) dan pengukuran akhir (posttest) 2) Terdapat peningkatan tingkat sedang (dengan kriteria $\mathrm{N}$-Gain) hasil belajar peserta didik yang menggunakan metode Cooperative Learning tipe Group Investigation pada pengukuran awal (pretest) dan pengukuran akhir (posttest) 3) Terdapat perbedaan yang signifikkan antara hasil belajar peserta didik yang menggunakan metode Active Learning tipe Problem Solving dengan metode Cooperative Learning tipe Group Investigation pada pengukuran akhir (posttest).

Kata Kunci: Hasil Belajar Peserta Didik, Problem Solving, Group Investigation 


\section{PENDAHULUAN}

Seiring dengan lajunya pembangunan dan perkembangan ilmu pengetahuan dan teknologi pada abad ini, ternyata dalam dunia pendidikan juga mengalami perkembangan yang sangat pesat. Oleh karena itu sudah sewajarnyalah bagi negara Indonesia sebagai negara yang sedang berkembang harus mengikuti atau memberi perhatian yang serius di sektor pendidikan, dimulai sejak dari pendidikan dasar sampai perguruan tinggi, baik di sekolah negeri maupun swasta, formal maupun nonformal. Pendidikan memegang peranan yang sangat penting dalam upaya mempersiapkan sumber daya manusia (SDM) yang berkualitas. Menurut Undang-Undang Nomor 20 Tahun 2003 tentang Sistem Pendidikan Nasional (dalam Himpunan Lengkap Undang-Undang Sistem Pendidikan Nasional, 2014: 9) menyebutkan bahwa: Pendidikan adalah usaha sadar dan terencana untuk mewujudkan suasana belajar dan proses pembelajaran agar peserta didik secara aktif mengembangkan potensi dirinya untuk memiliki kekuatan spiritual keagamaan, pengendalian diri, kepribadian, kecerdasan, akhlak mulia, serta keterampilan yang diperlukan dirinya, masyarakat, bangsa dan Negara.

Sumber daya manusia yang berkualitas sangat diperlukan untuk menunjang pembangunan, bisa bersaing di era global dan persaingan di segala bidang kehidupan yang semakin ketat. Jika Indonesia tidak ingin kalah bersaing dengan negara-negara lain, maka usaha-usaha peningkatan mutu sumber daya manusia hendaknya segera dilakukan. Pembelajaran di SMK Bahrul 'Uluum Kawali sudah terdapat kelompok belajar dalam kelas tetapi peserta didik masih terfokus mengerjakan soal secara mandiri, jarang adanya diskusi antar peserta didik. Jika kegiatan seperti itu terus berlanjut, besar kemungkinan persepsi peserta didik tentang arti penting akuntansi hanya sekedar sebagai kegiatan pencatatan. Sehubungan dengan hal itu maka perlu diperoleh solusinya. Salah satunya adalah diperlukan metode pembelajaran yang telah teruji realibilitas dan validitasnya. Sesuai dengan karakteristiknya pembelajaran akuntansi yang memerlukan ketelitian, kecermatan, tanggungjawab, berfikir kritis, kerjasama tim, pemecahan masalah serta motivasi maka dengan pendekatan konstruktivisme sangat sesuai untuk pembelajaran akuntansi, salah satunya dengan menggunakan metode pembelajaran aktif (Active Learning) dan pembelajaran kooperatif (Cooperative Learning).

Menurut Cahyo (2013:136) "Active learning (pembelajaran aktif) merupakan suatu pendekatan dalam pengelolaan sistem pembelajaran melalui cara-cara belajar yang aktif menuju belajar yang mandiri”. Peserta didik dalam melakukan pembelajaran aktif dapat menggunakan sumber daya di luar pengajar seperti perpustakaan, internet, wawancara, atau fokus group untuk memperoleh informasi. Dalam penerapan strategi belajar aktif, seorang pendidik harus mampu membuat pelajaran yang diajarkan itu menantang dan merangsang daya cipta peserta didik untuk menemukan serta mengesankan bagi peserta didik (Suherman, 2020). 
Hasil penelitian (Setiawan, 2016) bahwa peningkatan peningkatan hasil belajar dari siklus I sebesar $79,41 \%$ menjadi $85,30 \%$ pada siklus II naik $5,89 \%$. Peningkatan ini telah mencapai ketuntasan belajar klasikal sebesar $85 \%$. Sedangkan keaktifan belajar peserta didik mengalami peningkatan dari siklus I sebesar 53,92\% menjadi 74,50\% pada siklus II naik sebesar 20,58\%. Dari hasil analisis tersebut menunjukkan bahwa Pembelajaran Kooperatif Tipe Group Investigation dapat meningkatkan hasil belajar dan belajar peserta didik pada Mata Pelajaran Ekonomi kelas X SMA. Selanjutnya hasil penelitian penerapan model pembelajaran cooperative learning tipe group investigation berbasis multimedia meningkatkan hasil belajar siswa dan aktivitas belajar siswa pada mata pelajaran sistem pengaturan refrigerasi. (Raden I. Saputra, Syamsuri Hasan, Maman Rakhman, 2014).

Menurut Bern dan Erickson (dalam Kokom Komalasari, 2014:62) berpendapat bahwa "Cooperative Learning merupakan strategi pembelajaran yang mengorganisir pembelajaran dengan menggunakan kelompok belajar kecil di mana siswa bekerja bersama untuk mencapai tujuan pembelajaran". Pada metode ini peserta didik diberi kesempatan untuk berkomunikasi dan berinteraksi sosial dengan temannya untuk mencapai tujuan pembelajaran, sementara guru bertindak sebagai motivator dan fasilitator aktivitas peserta didik. Rata-rata nilai pretest mata pelajaran akuntansi di kelas X Ak SMK Bahrul 'Uluum Kawali tahun ajaran 2017/2018 hanya ada 1 orang peserta didik yang mencapai nilai KKM atau sebanyak 5,88\% yang mencapai nilai KKM. Sehingga nilai-nilai tersebut dikatakan belum optimal. Sulitnya memahami kompetensi keahlian akuntansi bisa disebabkan oleh dua hal atau salah satu dari: Pertama, metode pembelajaran yang diterapkan kurang atau bahkan tidak tepat sehingga peserta didik tidak mampu memahami materi yang disampaikan. Kedua, materi yang diajarkan tidak mudah dipahami peserta didik karena adanya konsep yang ditawarkan dalam materi tidak sejalan dengan pola pikir peserta didik (Suherman, 2019.

\section{KAJIAN PUSTAKA}

Proses adalah kegiatan yang dilakukan oleh peserta didik dalam mencapai tujuan pengajaran, sedangkan hasil belajar adalah kemampuan-kemampuan yang dimiliki siswa setelah ia menerima pengalaman belajarnya" (Sudjana, 2012:22). Tujuan pembelajaran pada dasarnya merupakan harapan, yaitu apa yang diharapkan dari peserta didik sebagai hasil belajar. Menurut Sudjana (2012:3) "Hasil belajar peserta didik pada hakikatnya adalah perubahan tingkah laku". Tingkah laku sebagai hasil belajar dalam pengertian yang luas mencakup bidang kognitif, afektif, dan psikomotoris. Djamarah (2010:105) mengatakan bahwa: Yang menjadi petunjuk suatu proses belajar mengajar dianggap berhasil adalah sebagai berikut: 1) Daya serap terhadap bahan pengajaran yang diajarkan mencapai prestasi tinggi, baik secara individual maupun kelompok; 2) Perilaku yang digariskan dalam tujuan pengajaran/instruksional khusus telah dicapai oleh siswa, baik secara individual maupun kelompok. Clark (dalam Sudjana, 2014:39) bahwa "hasil belajar peserta didik di sekolah 70\% dipengaruhi oleh kemampuan 
peserta didik dan 30\% dipengaruhi oleh lingkungan. Sekolah merupakan sistem yang terdiri atas serangkaian komponen yang saling terkait, dan membutuhkan masukan dari lingkungan untuk melakukan proses transformasi serta mengeluarkan hasil (out put) (Suherman, 2016).

Menurut Sanjaya (2011:147) Metode adalah cara yang digunakan untuk mengimplementasikan rencana yang sudah disusun dalam kegiatan nyata agar tujuan yang telah disusun tercapai secara optimal. Djamarah (2010:75) pemilihan dan penentuan metode dalam kegiatan belajar mengajar, dengan uraian bertolak dari: Nilai stategi metode, Efektifitas penggunaan metode, Pentingnya pemilihan dan penentuan metode dan Faktor-faktor yang mempengaruhi pemilihan metode.

Menurut Silberman (dalam Cahyo, 2013:137) menyatakan bahwa "Active Learning adalah sebuah kesatuan sumber kumpulan strategi-strategi pembelajaran yang komprehensif yang meliputi berbagai cara untuk membuat peserta didik menjadi aktif. Problem Solving adalah satu strategi yang mendorong peserta didik mengawasi langkah-langkah yang mereka gunakan dalam memecahkan satu masalah" (Cahyo, 2013:264). Menurut Sudjana (2014:85) "problem solving bukan hanya sekedar strategi mengajar tetapi juga merupakan suatu metode berfikir, sebab dalam problem solving dapat menggunakan metodemetode lainnya dimulai dengan mencari data sampai kepada menarik kesimpulan

\section{METODE PENELITIAN}

Dalam penelitian ini penulis menggunakan metode kuantitatif, yaitu data yang berbentuk angka. "Bentuk desain eksperimen yang digunakan dalam penelitian ini adalah Quasi Eksperimen, yang dilakukan dengan memberikan perlakuan kepada subjek penelitian kemudian memberikan tes pada subjek penelitian" (Husaini \& Purnomo dalam Marya, 2011:41). Didalam penelitian ini penerapannya adalah para peserta didik kelas X Ak 1 dalam proses pembelajaran pendidik menerapkan metode Active Learning tipe Problem Solving kemudian para peserta didik tersebut di tes secara tertulis tentang materi yang disampaikan oleh pendidik. Sedangkan para peserta didik kelas $\mathrm{X}$ Ak 2 dalam proses pembelajaran pendidik menerapkan metode Cooperative Learning tipe Group Investigation. Kedua kelas adalah kelas eksperimen, tidak ada kelas kontrol.

\section{HASIL PENELITIAN DAN PEMBAHASAN}

1. Hasil Belajar Peserta Didik Menggunakan Metode Problem Solving Pada Pengukuran Awal (Pretest) dan Pengukuran Akhir (Posttest) Pada Mata Pelajaran Akuntansi Kelas Eksperimen 1 (X Ak 1) SMK Bahrul 'Uluum Kawali.

Dalam metode Active Learning tipe Problem Solving peserta didik dilibatkan secara langsung dalam proses pembelajaran dan diberikan masalah yang pada dasarnya merupakan suatu hambatan atau rintangan yang harus disingkirkan, atau pertanyaan yang harus dijawab atau dipecahkan. Hal ini terjadi karena metode Active Learning tipe Problem Solving merupakan metode 
pembelajaran yang menitikberatkan pada peserta didik untuk belajar aktif. Penerapan metode Active Learning tipe Problem Solving disambut baik oleh peserta didik, hal ini terlihat dari peningkatan hasil pembelajaran juga dari sikap peserta didik yaitu adanya interaksi antar peserta didik, berani mencari, mempertanyakan sesuatu, menyelidiki jawaban atas suatu masalah yang diberikan oleh pendidik serta dapat mengelola dan menyampaikan hasil perolehannya secara komunikatif.

2. Hasil Penelitian Tentang Peningkatan Hasil Belajar Peserta Didik Menggunakan Metode Cooperative Learning Tipe Group Investigation Pada Pengukuran Awal (Pretest) dan Pengukuran Akhir (Posttest) Pada Mata Pelajaran Akuntansi Kelas Eksperimen 1 (X Ak 1) SMK Bahrul 'Uluum Kawali.

Dalam pelaksanaan proses pembelajaran metode Cooperative Learning tipe Group Investigation peserta didik dibagi ke dalam beberapa kelompok, satu kelompok beranggotakan 4 (empat) orang peserta didik setelah itu tiap kelompok diberi lembar kerja atau tugas untuk dikerjakan bersama anggota kelompoknya dan boleh menggunakan berbagai sumber, baik yang terdapat di dalam maupun di luar sekolah dalam menyelesaikan tugas tersebut. Para peserta didik menganalisis berbagai informasi yang diperoleh dan merencanakan agar dapat diringkas dalam suatu penyajian yang menarik di depan kelas. Lalu semua kelompok menyajikan suatu presentasi yang menarik dari berbagai topik yang telah ditugaskan.Dan pendidik beserta peserta didik melakukan evaluasi mengenai kontribusi tiap kelompok terhadap pekerjaan kelas sebagai suatu keseluruhan. Setelah proses pembelajaran menggunakan metode Cooperative Learning tipe Group Investigation ada peningkatan dilihat dari pengukuran akhir (posttest) nilai ratarata peserta didik di atas nilai kriteria ketuntasan minimal. Peningkatan hasil pembelajaran juga terlihat dari sikap peserta didik yaitu peserta didik lebih aktif dan kreatif memperoleh pengetahuan dari berbagai sumber baik itu di dalam sekolah maupun di luar sekolah serta dapat membuat penyajian materi serta pembahasannya menarik.

3. Hasil Penelitian Tentang Perbedaan Hasil Belajar Peserta Didik Menggunakan Metode Active Learning Tipe Problem Solving dengan Metode Cooperative Learning Tipe Group Investigation Pada Pengukuran Awal (Pretest) dan Pengukuran Akhir (Posttest) Pada Mata Pelajaran Akuntansi Kelas Eksperimen 1 (X Ak 1) dan Kelas Eksperimen 2 (X Ak 2) SMK Bahrul 'Uluum Kawali.

Berdasarkan hasil penelitian yang dilakukan oleh peneliti dapat diketahui bahwa hasil belajar peserta didik yang menggunakan metode Active Learning tipe Problem Solving memiliki nilai rata-rata 83 lebih tinggi dari metode Cooperative Learning tipe Group Investigation yang hanya memiliki nilai rata-rata 79. Berdasarkan kategori $\mathrm{N}$-Gain peserta didik yang memiliki kategori tinggi pada peserta didik eksperimen 1 (Ak 1) lebih banyak yaitu 12 orang peserta didik dibandingkan dengan peserta didik kelas eksperimen 2 (Ak 2) lebih sedikit sebanyak 10 orang peserta didik. Perbedaan hasil belajar peserta didik yang 
menggunakan metode Active Learning tipe Problem Solving terjadi karena pada metode Active Learning tipe Problem Solving peserta didik dituntut berani tampil di depan, lebih aktif dan kreatif memperoleh pengetahuan dari berbagai sumber baik itu di dalam sekolah maupun di luar sekolah serta dapat membuat penyajian materi serta pembahasannya menarik. Dalam pembelajaran metode Cooperative Learning tipe Group Investigation peserta didik dikelompokkan pada tiap-tiap kelompok yang beranggotakan 4 orang peserta didik dalam setiap kelompoknya dan peserta didik diberi lembar kerja yang harus di kerjakan dan di diskusikan. Setelah selesai mengerjakan lembar kerja tersebut setiap kelompok diberikan kesempatan untuk menampilkan hasil diskusinya dengan menarik dan sekreatif mungkin.

Dengan demikian metode Active Learning tipe Problem Solving dan metode Cooperative Learning tipe Group Investigation memiliki peran yang positif dalam menentukan hasil belajar peserta didik. Akan tetapi hasil belajar peserta didik yang menggunakan metode Active Learning tipe Problem Solving lebih tinggi hasilnya dibandingkan dengan hasil belajar peserta didik yang menggunakan metode Cooperative Learning tipe Group Investigation.

\section{SIMPULAN}

Berdasarkan hasil penelitian, maka dapat penulis simpulkan sebagai berikut: 1) Terdapat peningkatan hasil belajar peserta didik yang menggunakan metode Active Learning tipe Problem Solving pada pretest dengan posttest di kelas eksperimen 1 pada mata pelajaran akuntansi SMK Bahrul 'Uluum Kawali sebesar 0,8 termasuk ke dalam kriteria tinggi dan persentase peningkatannya sebesar $75 \%$. 2) Terdapat peningkatan hasil belajar peserta didik yang menggunakan metode Cooperative Learning tipe Group Investigation pada pretest dan posttest pada kelas eksperimen 2 pada mata pelajaran akuntansi SMK Bahrul 'Uluum Kawali sebesar 0,6 termasuk ke dalam kriteria sedang dan persentase peningkatannya sebesar 64\%. 3) Terdapat perbedaan hasil belajar peserta didik yang menggunakan metode Active Learning tipe Problem Solving dengan metode Cooperative Learning tipe Group Investigation pada pretest dan posttest pada kelas eksperimen 1 dan eksperimen 2 pada mata pelajaran akuntansi kelas X Ak SMK Bahrul 'Uluum Kawali. Adapun persentase perbedaan hasil belajar peserta didik diantara kedua metode tersebut yaitu sebesar $8,54 \%$. Jadi hasil belajar peserta didik dengan menggunakan metode Active Learning Tipe Problem Solving lebih unggul untuk diterapkan pada mata pelajaran akuntansi di SMK Bahrul 'Uluum Kawali daripada metode Cooperative Learning Tipe Group Investigation artinya kelas eksperimen 1 lebih unggul dibanding kelas eksperimen 2.

\section{DAFTAR PUSTAKA}

[1] Agus, Cahyo. (2013). Panduan Aplikasi Teori Belajar. Jakarta. PT. Diva Press. 
[2] Djamarah, Syaiful, B. \& Aswan Zain. 2010. Strategi Belajar Mengajar. Jakarta: Rineka Cipta.

[3] Husaini Usman dan Purnomo Setiady, Metodologi Penelitian Sosial, ( Jakarta : PT Bumi Aksara, 2006 )

[4] Komalasari, Kokom. 2014. Pembelajaran Kontekstual. Bandung: PT. Refika Aditama.

[5] Mulyana E, Suherman A, Tetep, et.al (2020). Training on Developing Children's Social Character Through Sundanese Cultural Values. http://ejournals.fkwu.uniga.ac.id/index.php/IJCE/article/download/158/86

[6] Raden I. Saputra, Syamsuri Hasan, Maman Rakhman, (2014). Penerapan Model Pembelajaran Cooperative Learning Tipe Group Investigation Berbasis Multimedia Untuk Meningkatkan Hasil Belajar Siswa Pada Mata Pelajaran Sistem Pengaturan Refrigerasi. https://ejournal.upi.edu/index.php/jmee/article/view/3743

[7] Sanjaya, Wina. 2008. Kurikulum dan Pembelajaran. Jakarta: Kencana Prenada Media Group.

[8] Sudjana, Nana. 2012. Penilaian Hasil Proses Belajar Mengajar. Bandung: PT. Remaja Rosdakarya.

[9] Sudjana. 2000. Statistika. Bandung: Tarsito.

[10] Suherman A, Susanti Y, Fauzi A. (2019). Model Pembelajaran Arias Dengan Seting Kooperatif Tipe Jigsaw Terhadap Hasil Belajar. https://journal.institutpendidikan.ac.id/index.php/journalcss/article/viewFile/ $698 / 548$

[11] Suherman A, Yuyun S. (2020). Penggunaan Model Pembelajaran Inkuiri Tipe Expository Dengan Tipe Discovery Terhadap Hasil Belajar. https://journal.institutpendidikan.ac.id/index.php/journalcss/article/viewFile/ $784 / 657$

[12] Suherman A. (2016). Analisis Penganggaran Pendidikan Dan Keterampilan Komunikasi Kepala Sekolah Terhadap Kepuasan Kerja Guru Smkn Kabupaten Ciamis. https://jurnal.unigal.ac.id/index.php/edukasi/article/download/1012/905

[13] Setiawan. (2016). Penerapan model pembelajaran kooperatif tipe investigasi kelompok untuk meningkatkan hasil belajar dan keaktifan peserta didik pada mata pelajaran ekonomi di kelas X 6K2 SMA Negeri 10 Malang. http://library.um.ac.id/ptk/index.php?mod=detail\&id=75643.

[14] Undang-Undang Nomor 20 Tahun 2003 tentang Sistem Pendidikan Nasional 